\title{
LA PERSONA, SUJETO ÉTICO-JURÍDICO
}

\author{
PERSON: ETHICAL-LEGAL SUBJECT
}

\section{Por María del Carmen Platas Pacheco*}

RESUMO: O conceito de pessoa é relevante não somente da perspectiva ética ou histórica, mas, também, da perspectiva jurídica, como centro de imputação de direitos e obrigações. Entretanto, a trascendência desta noção supera qualquer postura exclusivista, precisamente porque se em torno do ser humano tem sentido a orden social e as instituições que a regem, estas não préexistem a pessoa, de maneira que somente é possível comprender o sujeito de direito desde a integralidde de seu ser, quer dizer, advertendo o componente moral que subjaz ao jurídico e ambos enfoques imersos na temproalidade da história.

PALAVRAS-CHAVE: pessoa; sujeto de direito; temporalidade histórica.

ABATRACT: The concept of person is relevant from either ethical or historical or legal perspective as the center of imputation of rights and obligations. However, the transcendence of such notion goes beyond any exclusivist approach, precisely because social order and institutions that rule it only

\footnotetext{
* Professora da Universidad Nacional Autónoma de México - UNAM.
}

make sense around human being, that is, those do not exist before the person. Then, it is only possible to understand legal subject since the integrality of his or her being, that is, highligthing the moral component that undergoes the legal one and both approches from the perspective of historical temporality.

KEYWORDS: person; legal subject; historical temporality.

RESUMO: El concepto de persona es relevante no solo desde la perspectiva ética o histórica, sino también desde la jurídica, como centro de imputación de derechos y obligaciones, sin embargo, la trascendencia de esta noción supera cualquier postura exclusivista, precisamente porque si en torno del ser humano tiene sentido el orden social y las instituciones que lo rigen, éstas no preexisten a la persona, de manera que solo es posible entender el sujeto de derecho desde la integralidad de su ser, es decir, advirtiendo el componente moral que subyace al jurídico, y ambos enfoques inmersos en la temporalidad de la historia."

PALABRAS-CLAVE: persona; sujeto de derecho; temporalidad histórica. 
Hay en mis venas gotas de sangre jacobina, pero mi verso brota de manantial sereno; $y$, más que un hombre al uso que sabe su doctrina, soy, en el buen sentido de la palabra, bueno. Antonio Machado

\section{La persona no sólo es el protagonista} del orden social, ésta es una afirmación que de suyo es determinante en la comprensión del orden societario como un orden humano, racional y moral a un tiempo, supone, además, otra implicación y ésta consiste en afirmar que con sus actos la persona se construye o se destruye y en esa misma medida impacta a la sociedad. Precisamente de la consideración de esta realidad surge la subordinación del derecho a la ética, evidentemente estamos en presencia de dos tipos de ciencias humanas, una práctica y otra teórica, sin embargo, ambas son ciencias, lo que implica que el nivel de sus conocimientos es universal.

El debate científico es sobre todo debate conceptual, cuando una ciencia nace, nace con su propio lenguaje y sus propios códigos. La ciencia jurídica moderna inmediatamente marcó cuáles eran sus confines y sus parámetros, el debate ha permanecido hasta ahora, y ha resurgido como posmodernismo, ${ }^{1}$

1 Para algunos como Berdiaeff es "una nueva edad media" si el renacimiento ha terminado y no hemos pasado a una nueva época esto quiere decir que la actual es transitoria y por tanto intermedia: "La historia moderna es una empresa que ha fracasado, que no ha glorificado al hombre como hacía esperar. Las promesas del humanismo no han sido cumplidas [...] no ha fortalecido, sino que ha debilitado al hombre; tal es el desenvolvimiento paradójico de la historia moderna. A través de su autoafirmación, el hombre se ha perdido, en lugar de encontrarse [...] en el fondo toda la historia moderna ha sido una dialéctica inmanente de autorrevelación, y después, de autonegación de los principios que habían motivado su nacimiento [...] contradicción destructora del humanismo que por un lado engrandecía al hombre atribuyéndole fuerzas aunque éste quiera sólo definirse como estado anímico, quizá como hipermodernismo o supermodernismo, que busca reconceptualizar nociones canceladas por el discurso moderno como el de comunidad. Una cosa cierta es que en la discusión académica, por descifrar las diferentes épocas y sus bases ideológicas, el centro del debate es siempre la persona, muchas cosas, aún a nivel práctico dependerán de la conceptualización de ésta, una de ellas es el derecho, en el paso del antiguo al moderno, cambiaron muchas cosas, pero la principal sin dudas es el papel de la persona ligado a lo que significaba en una y otra época ser persona. ${ }^{2}$

Las anteriores reflexiones, no parecen presentar dificultad; sin embargo, en diversas ocasiones el estudio de la ciencia del derecho se reduce al de formalismos tan abstractos que terminan por dejar al margen o excluir la necesidad de consideración de lo humano, es decir, de la persona; ${ }^{3}$ y la ética, por su parte, en ocasiones tan alejada de su auténtico objeto - el bien de los actos humanos- para pretender que es mejor "aterrizar" el valor de las acciones en la endeble superficie del consenso, a este respecto son elocuentes las doctrinas éticas de Savigni, Kelsen ${ }^{4}$, sólo por

ilimitadas y por el otro no veía en él más que un ser limitado y subordinado que ignoraba la libertad espiritual." BERDIAEFF, Nicolás, Una nueva edad media. Reflexiones acerca de los destinos de Rusia y Europa, Apolo, Barcelona, 1933, pp. 11-24.

2 NARVÁEZ HERNÁNDEZ, José Ramón, La persona en el derecho civil (historia de un concepto jurídico), Porrúa, México, 2005, p. 11

3 Cfr. BERLÍN, Isaiah, El fuste torcido de la humanidad. Capítulos de historia de las ideas, Península, Barcelona, 1992, pp. 85-101. Estas ideas son derivadas de doctrinas cuyas bases se remiten -entre otras doctrinas- a las consideraciones de Hume acerca del hombre y las relaciones causales de sus actos.

4 Cfr. REALE, Giovanni y ANTISERI, Darío, Historia del pensamiento filosófico y científico, T. III, Barcelona, Herder, 1995, pp. 795-797, 
referir ejemplos de gran impacto jurídico, de este modo el estudio de la dependencia esencial del derecho de la ética se ha diluido $\mathrm{y}$, en consecuencia, las exigencias morales parecen resbalar en el incierto espacio de la especulación filosófica como si ésta no ofreciera rumbos y destinos, también de implicaciones prácticas.

De manera que La persona no es, sino que se constituye en la relación interpersonal. La persona se constituye en la comunidad. El constitutivo formal, la raíz y causa de la dignidad personal y de las perfecciones personales, es la relación social" 5 , sólo para efectos de estudio podemos pensar en la persona, pero de hecho ésta siempre se encuentra vinculada a otros que en cierto sentido la determinan y que siempre la constituyen.

$\mathrm{Al}$ respecto son elocuentes las palabras del maestro Del Vecchio:

La descomposición empírica de la personalidad, que se ha realizado en la Filosofía en general, ha tenido su exacta correspondencia en la Filosofía del Derecho. Si es verdad que, como ya hemos notado, las instituciones jurídicas y políticas de nuestra época, de hecho se han inspirado en la idea de los derechos esenciales de la persona, que fue el laborioso fruto del largo proceso anterior, y, lo que también es digno de notar, dichas instituciones todavía tienden, en su moderno desenvolvimiento, a realizar cada vez más, las teorías dominantes en la Filosofía del Derecho rechazan hoy esta idea y niegan la sustancialidad jurídica del ser humano, como por otro lado se ha negado su sustancialidad psicológica. También en este punto se procede por medio de una exteriorización, esto es, se reduce el ser al

5 FORMENT, Eudaldo, Personalismo medieval, Edicep, Valencia, 2002, p. 275. fenómeno, y se declara que el Derecho sólo es un hecho histórico relativo, una función de necesidades y fuerzas variables y no una verdad objetiva y constante, capaz de ser conocida por la razón. No podía ocurrir otra cosa; porque, si se admite que la naturaleza humana no existe como ser sino tan sólo en aspectos y contingencias concretas, es imposible admitir un principio jurídico universalmente y adecuado a ella. ${ }^{6}$

A la luz de estas reflexiones, resulta indispensable la consideración de la persona en su integridad de sujeto que actúa para intentar abordad a cabalidad este estudio inicial de la ética jurídica, ya que la persona es la condición de posibilidad del derecho, es el sujeto que protagoniza la vida societaria.

Cualquiera de los términos que expresan de algún modo un aspecto de la realidad jurídica hacen relación a la persona humana. Ella es el sujeto destinatario de la norma, el alguien que está obligado a cumplir la conducta establecida legalmente; es, en igual forma, el sujeto que tiene la facultad para exigir a otro u otros el cumplimiento de la prestación a la que están obligados; ella es también el ser real que puede decir que algo le corresponde como suyo. La persona se nos aparece así como la realidad fundamental a la que hace referencia el derecho. Es decir, que el derecho existe por y para la persona. Conocer lo que sea el derecho es aproximarnos a lo que sea la persona, saber lo que es la persona es adentrarnos en la fundamentación de la realidad jurídica. ${ }^{7}$

Mucho se ha escrito y reflexionado sobre el protagonismo jurídico de la persona, como si se tratara de un concepto unívoco y

6 DEL VECCHIO, Jorge, Persona, Estado y Derecho, Instituto de Estudios Políticos, Madrid, 1957, pp. 37-38.

7 HOYOSCASTAÑEDA, Ilva Myriam, La dimensión jurídica de la persona humana, Universidad de la Sabana, Colección Ensayos no. 3, Bogotá, 1990, p. 12. 
exento de las erosiones que son frecuentes en la configuración de nociones fundamentales, así adquieren su cabal significaciones las reflexiones que nos ofrece José Ramón Narváez:

En el siglo XIV comenzó el camino que llevó a la humanidad a redefinir el concepto de persona a través de una visión "toda centrada sobre particulares individualidades, tendida a liberarlas lo más posible de la humillación de las relaciones. Se entiende como, en este nuevo mundo protomoderno, se venga conscientemente a acuñar la idea de derecho subjetivo y se edifique sobre ella toda la construcción..." 8

Partimos pues de esta discordancia entre Persona/Sociedad que platea inmediatamente la reflexión del concepto moderno de persona y que será justamente 'la piedra en el zapato' del derecho moderno y que atraerá las críticas de las corrientes sociales y socialistas de la segunda mitad del siglo XIX que no lograron disolver la discordancia sino sólo cambiar el punto de partida de la discusión que entonces sería Sociedad/Persona. ${ }^{9}$

De esas disquisiciones, resulta una inversión de los conceptos que nubla o por lo menos hace menos evidente que el estudio de la moralidad de los actos humanos, es indispensable para entender en su integralidad a la persona como sujeto anterior y superior al derecho, la perspectiva jurídica compromete necesariamente la moral, de manera que todo acto jurídico tiene una dimensión moral, pero no todo acto moral tiene una dimensión jurídica, de donde se sigue que la persona es el destinatario de la norma precisamente porque es la condición de posibilidad del derecho; por consiguiente, el objeto de

8 GROSSI, Paolo, L'ordine giuridico medievale, Laterza, Roma-Bari, 2001, p. 85.

9 NARVÁEZ HERNÁNDEZ, José Ramón..., op. cit., p.13. nuestra noble ciencia es la deuda ante la que responde la norma como consecuencia ${ }^{10}$, así las cosas, la justicia se concreta en el saldo de la deuda, en dar a cada persona lo que le corresponde, es decir, lo suyo. Lo suyo es una noción hasta tal punto radical y primaria que sólo se deja reducir a la noción de persona. ${ }^{11}$ En consecuencia, cualquier noción de justicia que no parta de la persona, y por lo tanto, de lo debido, no tiene fundamento, simplemente estaremos en presencia de una postura relativista propia del escepticismo o del nihilismo. Si se prescinde de la persona humana y se especula en abstracto sobre la justicia tendría buena parte de razón el pesimista comentario de Pascal: "no existe nada de lo justo o de lo injusto que no cambie de calidad tan pronto se cambie de clima. Tres grados de elevación sobre el polo ponen de cabeza al derecho; un meridiano decide sobre la verdad...". ${ }^{12}$ La persona es el centro de nuestro estudio porque es la protagonista del orden social que el derecho regula.

Diversas nociones acerca de la persona se han formulado según el ámbito desde el cual se estudie -a saber: jurídico, ético, metafísico, psicológico, etcétera- es el modo en que se delimita conceptualmente. En el derecho, la persona se define como el sujeto de derechos y obligaciones, ${ }^{13}$ sin embargo, su fundamento

${ }^{10}$ Cfr. PlATAS PACHECO, María del Carmen, Filosofía del Derecho, Analogía de proporcionalidad, Porrúa, 2003, pp. 1-53.

11 HOYOS CASTAÑEDA, Ilva Myriam..., op. cit., p. 13.

12 PÉREZ VARELA, Víctor Manuel, Ser más humano, reflexiones sobre ética y derecho, Universidad Panamericana, Porrúa, México, 2005, p. 11.

13 Cfr. Nuevo Diccionario Jurídico Mexicano, UNAM, Porrúa, México, 2001, t. IV, voz: persona, p. 2845. 
se encuentra en la filosofía. Por esta razón, haremos un recorrido histórico de la definición de persona más adelante, ${ }^{14}$ pero por ahora partiremos de esta noción jurídica actual para plantear primero la relevancia de la misma en el contexto moral que para estas reflexiones es oportuno.

El concepto de persona jurídica tiene una larga y complicada historia. Es el fruto de una lenta y fatigosa elaboración conceptual, en la cual se refleja toda la historia de la dogmática y la experiencia jurídica (Orestano). Los varios significados de "persona", los de su equivalente griego (...) y sus derivaciones modernas han sido objeto de muchas controversias entre filólogos, juristas, filósofos y teólogos. En la actualidad "persona jurídica" es un término altamente técnico con el cual los juristas se refieren a una entidad dotada de existencia jurídica, susceptible de ser titular de derechos subjetivos, facultades, obligaciones y responsabilidades jurídicas". ${ }^{15}$

Según su sentido etimológico, sujeto significa lo que está debajo de, el término griego correspondiente es upokei/menon. ${ }^{16}$ Desde esta perspectiva, la persona es para el derecho el sujeto que subyace a los derechos y obligaciones, de manera que el sentido de sujeto es el equivalente de persona (hipóstasis) desde la cultura persa, que legó el concepto al griego y posteriormente al latín ${ }^{17}$, de manera que a la persona le corresponde una juridicidad natural, allí donde hay un hombre

${ }^{14}$ Vid infra. p. 6.

${ }^{15}$ Nuevo Diccionario Jurídico..., op. cit., T. IV, voz: Persona, p. 2845.

16 Diccionario Griego-Español, Editorial Sopena, Barcelona, 1999, voz: u4pokiemai, (hipokeímenon, es el participio pasivo), p. 1441.

17 Diccionario Manual Vox, Griego-Español, Barcelona, 1995, voz: u9to/stasij ewj, p. 610. singular y concreto hay un alguien que tiene derechos y deberes. Ser titular de derechos no es, por tanto, una consecuencia de la legislación positiva, es la expresión de la dignidad de la persona humana contemplada no sub ratione personalitatis sino sub specie iuris. ${ }^{18}$

La cita anterior equivale a afirmar que la juridicidad natural en la que se apoyan los derechos y deberes refleja las características de la persona. Una de ellas es la dignidad, que frecuentemente ha sido incomprendida a fuerza de triunfar, al menos en la reflexión, una concepción de lo humano que hace descansar su esencia en la inclusión en los repertorios formativos, de manera que existe porque el Estado y su aparato productor de normas le dan entidad, tarea y límites.

En este mundo moderno insular y legal a la vez, el individuo se convierte en un radicalismo y la ley en su certificado de existencia, en un binomio descifrable sólo en principios de autonomía de la voluntad, soberanía, espíritu de la ley, la voluntad del legislador es la voluntad popular, binomio que equivale siempre a dos excesos: individualismo y legalismo ${ }^{19}$ y que han originado las mitologías de la modernidad, como las llama Paolo Grossi "El proceso asume un carácter francamente liberatorio: individualización como liberación de las viejas y ahora sofocantes incrustaciones. A cada nivel, revistiendo ya todas las dimensiones del intrasubjetivo y del intersubjetivo. Asume el vestido de una liberación antropológica aquél variado pero improponible movimiento que tiende a cambiar de lugar de la conciencia a la voluntad la carga tipificante del sujeto,

${ }^{18}$ HOYOS CASTAÑEDA, Ilva Myriam..., op. cit., p. 32 .

19 Adelantamos una definición de Legalismo de Silvia Gasparini: "Instrumento de disimulación de desigualdades sustanciales" Appunti minimi di storia del diritto, 2. Età moderna e contemporanea, Imprimitur, Padova, 2002, p. 214. 
porque entre las dimensiones psicológicas la voluntad es la más independiente y aislante, encontrando su justificación al interior del sujeto mismo, a diferencia de la conciencia que lo proyecta hacia afuera y lo sumerge en el mundo de los objetos. Y es liberación social el tentativo de edificar la nueva sociedad sobre el individuo y sobre sus talentos personales, desvirtuandofinalmente los viejos contenedores comunitarios retenidos hasta entonces insustituibles e inaugurando una conciencia de la relación particular/colectividad que puede bien decirse prehumanística. Y es fruto de la conquistada liberación política la entidad que aparece fresca de fuerzas en el paisaje europeo del siglo XIV, desfachatada y arrogante, preocupada únicamente de quitar cada empacho a la propia acción política y de hacer las cuentas solamente consigo misma; una entidad que a este punto no es indebido llamar Estado. Individuo y Estado serán los futuros protagonistas del planeta moderno: mirar un poco más profundamente sobre sus procesos liberadores significará para nosotros aclarar los motivos del foso de discontinuidad que se está cavando justamente aquí, entre el siglo XIII y el XIV." ${ }^{20}$ Individuo aislado con su derecho a exigir delante al Otro, equivale a Estado soberano listo a defender su territorio a costa de lo que sea. ${ }^{21}$

No hemos de perder de vista, sin embargo, que la naturaleza racional del ser humano hace que le correspondan ciertos derechos y obligaciones, éstos implican su ser social, de manera que la convivencia exige por necesidad tanto unas libertades como sus límites, porque precisamente la persona se reconoce como sujeto en la relación con los demás.

${ }^{20}$ GROSSI, Paolo, Dalla società di società alla insularità dello Stato fra medioevo el età moderna, Instituto Universitario Suor Orsola Benincasa, Napoli, 2003, p.33 y ss.

${ }^{21}$ NARVÁEZ HERNÁNDEZ, José Ramón..., op. cit., pp. 15-16.
Así pues, en el terreno del derecho ser persona quiere decir ser reconocido por los demás en cuanto que constituyen una unidad social, y es este reconocimiento el que otorga unas capacidades de acción respecto de los demás. El carácter de persona es, pues, conferido por el sistema jurídico y social. Esta configuración social del carácter de persona, que el derecho romano formaliza de manera muy específica, está presente en la mayoría de las culturas, aunque con diversas variaciones. Con esta configuración social del carácter de persona se relacionan, en consecuencia, la mayoría de los estudios realizados desde la sociología o la antropología cultural e incluso, desde la psicología (..). Y en la misma línea se inscriben todos los estudios filosóficos que insisten en la necesidad de la intersubjetivdad para que el hombre se constituya existencialmente y se conozca a sí mismo como sujeto. ${ }^{22}$

Para el estudio de la ética en su aproximación jurídica, es indispensable considerar que la persona reside precisamente en esa conjunción de individualidad y de implicación social de sus actos, a la luz de esta perspectiva, la persona es el sujeto de la ética en primer lugar, en cuanto que es moralmente responsable de sus actos, y es, en segundo lugar, sujeto de la ley y el derecho en cuanto sus actos se realizan en el marco de un orden jurídico que los rige, así se explica que es a partir de la persona que los derechos tienen verificativo en el espacio societario.

Comprender la integridad de lo que la persona es, supone además hacerse cargo de su alteridad, por lo que el derecho es esencialmente referencia a otro. ${ }^{23} \mathrm{La}$ deuda establece el carácter de la relación jurídica

${ }^{22}$ ARREGUI, Jorge Vicente, y CHOZA, Jacinto, Filosofía del hombre, una antropología de la intimidad, Universidad de Navarra, RIALP, Madrid, 1993, p. 430.

${ }^{23}$ HOYOS CASTAÑEDA, Ilva Myriam..., op. cit., p. 27. 
entre una persona y otra. El tener algo mío, y que otro tenga lo suyo, sólo es posible por la alteridad, esto supone a su vez individualidad y alteridad de la persona. La alteridad que caracteriza la realidad jurídica es posible porque la persona es un ser naturalmente relacionado con otros seres, porque ella misma tiene como propia una dimensión jurídica: son las cosas que tienen como suyas las que referidas a otros se constituyen en derecho. Así pues, la relación jurídica es ordenación entre dos o más sujetos por razón de las cosas. ${ }^{24}$

Las tres características de la persona se interrelacionan de tal forma que no es posible remitirse a una sin considerarla subordinada a las otras. No obstante, la dignidad puede pensarse separada en el sentido de que es la más relevante para el derecho, porque a partir de ella se reconoce la igualdad entre las personas y se ejercen los derechos y las obligaciones que le son inherentes.

La dignidad es una palabra clave en la Ética y en el Derecho. Con toda razón, la Declaración Universal de los Derechos Humanos proclama en el artículo primero que "todos los seres humanos han nacido libres e iguales en dignidad y derechos". 25

La dignidad es el referente obligado para la conservación de la paz y la justicia. Es el criterio que sustenta la seguridad jurídica como valor social y jurídico de gran trascendencia, de manera que las leyes existen para garantizar el respeto a la dignidad $\mathrm{y}$, en consecuencia, los jueces deben interpretar los hechos y las normas a la luz del respeto que el concepto de dignidad supone, la

\footnotetext{
${ }^{24}$ Ibidem, p. 27.

${ }^{25}$ PÉREZ VARELA, Víctor Manuel..., op. cit., p. 23.
}

formulación de los derechos y las exigencias de las obligaciones tienen como referente la adecuada consideración de la naturaleza humana, como expresión de su dignidad. $L a$ justicia, la paz y seguridad jurídica, no serían más que la dignidad humana en acción. Estos derechos son universales, inviolables e inalienables. ${ }^{26}$

La importancia dada en el derecho a la dignidad en cuanto característica de la persona se refleja en la siguiente afirmación de Víctor Manuel Pérez Varela: proteger o salvaguardar la dignidad humana sería el objetivo o fin al que debe aspirar toda legislación ${ }^{27}$, de manera que el orden jurídico se prueba a sí mismo y a sus aplicadores en la medida en que es capaz de concretar en los juicios el respeto y promoción de la dignidad humana.

Tal como da cuenta la historia, el genuino reconocimiento de la naturaleza de la persona ha ocurrido en el devenir de los siglos. La dignidad, es decir, el reconocimiento que de la persona hace el que le concede el derecho, sólo era atribuida en principio a algunos hombres; las mujeres y los esclavos no eran considerados ciudadanos, porque ni siquiera eran identificados con el concepto de persona:

La naturaleza humana, especialmente por obra de la especulación griega, (...) fue considerada en sus más generales determinaciones; pero generalmente, en lo que se refiere al Derecho, tanto en Grecia como en Roma, el hombre siempre estaba identificado con el ciudadano. Precisamente porque de aquella especulación resultaba como una exigencia absoluta para el individuo el que éste perteneciera al Estado, la

\footnotetext{
${ }^{26}$ Ibidem, p. 23.

${ }^{27}$ Ibidem, p. 23.
} 
personalidad humana no aparecía verdaderamente envuelta a los ojos de aquéllos filósofos, salvo los que de hecho ya poseían los derechos civiles. El concepto de lo que por su propia naturaleza es el hombre, viene, como de reflejo, a mitigar la condición de quienes no son ciudadanos, de los extranjeros y esclavos, a los cuales, de hecho, jamás se trató como cosas, según deseaba la pura construcción dogmática del Derecho antiguo. Sin embargo, en razón a su inmediato contenido, tanto la Filosofía griega, como la Jurisprudencia romana, jamás consideraron la personalidad jurídica del hombre sino en cuanto la hallaron ya reconocida dentro de los límites del Estado. ${ }^{28}$

Desde la consideración de la etimología y de la genealogía, el concepto de persona hace referencia a un tipo de sujeto que posee voz, es decir, que se le reconoce porque participa o, en otras palabras, la participación societaria, ciudadana supone valor para los demás. Por ello no se les consideraba a las mujeres y los esclavos como personas, porque jurídicamente no participaban, pues no tenían voz ni voto dentro de la polis. La noción de persona deriva de una analogía con el teatro donde lo importante es la voz que compromete el actor en la representación del papel que le corresponde.

El origen del término latino persona proviene, al parecer, de la palabra griega prósopon (sic), que significa máscara y con la cual se designaba la máscara con que los actores usaban en el teatro para representar diversos papeles o personajes. Los términos «actor», «representar» $y$ «papel» (lo que en filosofía anglosajona contemporánea se llama «rol») están muy cargados de significado jurídico en toda la historia del derecho, desde la época clásica hasta nuestros días. ${ }^{29}$

${ }^{28}$ DEL VECCHIO, Jorge..., op. cit., pp. 7-8.

29 RREGUI, Jorge Vicente, CHOZA, Jacinto..., op . cit., p. 429.
En consecuencia, etimológicamente, persona significa máscara. El término viene del latín personae $e^{30}$ que a su vez tiene su origen en el etrusco phersu; y éste en el griego prósopon $^{31}$. Las máscaras se empleaban originalmente en el teatro, eran el modo para hacer explícito el carácter - o al menos el sentir - del personaje; además se diseñaban para amplificar el sonido, es decir, hacían las veces de un altavoz o micrófono. Debido a la distancia entre el espectador y el actor, la máscara ha representado un recurso muy útil al antiguo arte dramático.

En el itinerario y las consideraciones que venimos haciendo sobre el concepto de persona como sujeto ético y jurídico a un tiempo, es relevante señalar que la forma en que se fusiona o integra la tradición europea en el contexto de la cultura jurídica mexicana, debe ser sensible a la asimilación que supuso el encuentro de Europa y América.

\section{El descubrimiento de América dio oportunidad a replantear el concepto de ser humano y contribuyó al debate sobre la persona, el fenómeno del descubrimiento implicó la suma y revoltura de tantas ideologías y en un sentido el inicio de una nueva época, la moderna; pero por otro lado, y sobre todo en el ámbito jurídico, se siguieron conservando (con salvedades y reformas) las viejas figuras que siglos más tarde el derecho moderno desecharía del todo con un código. ${ }^{32}$}

Según Amélie Rorty, el sentido de persona tiene dos fuentes: la ya explicada del teatro,

${ }^{30}$ Diccionario ilustrado Latino-Español, EspañolLatino, VOX, Barcelona, 1999, voz: persona, -ae, p. 367.

31 Diccionario Manual..., op. cit., voz: proswton7ou, p. 516. Los sentidos de prósopon, ou, son: rostro, faz, cara, frente; figura, forma, aspecto, aire; superficie; máscara, papel; persona, hombre; fachada.

32 NARVÁEZ HERNÁNDEZ, José Ramón..., op. cit., p. 17 
y la ley y el descubrimiento. Un actor lleva máscaras, literalmente personae, por las cuales pasa el sonido y los diferentes papeles que desempeña (..). La persona está, así, detrás de sus papeles, los elige y es juzgada por sus elecciones y por su aptitud para escenificar su personae dentro de una estructura global que es el desenvolvimiento de su drama. La idea de persona es la idea de un centro unificado de elección y acción, la unidad con la que se relaciona la responsabilidad legal y deontológica. Al haber elegido, la persona actúa, y es, por ende, legal y moralmente responsable. En la idea de acción es donde se reúnen las fuentes legales y teatrales del concepto de persona. ${ }^{33}$

La persona, para expresarse, emplea recursos similares y en la vida cotidiana ejerce o desempeña diferentes papeles sociales como si requiriera de una máscara que le ayude a comunicarse y le permita teñir sus actos de una emotividad específica. Conviene aclarar que la máscara no necesariamente es expresión de falsedad, es más bien un rostro que no refleja nítidamente la intimidad, porque la persona ejerce dominio sobre sí misma y no está obligada a mostrar su interior. ${ }^{34}$

33 Diccionario de ética y filosofía moral, Fondo de Cultura Económica, México, 1997, V. I, voz: Identidad moral, p. 767.

34 Cfr. YEPES STORK, Ricardo, ARANGUREN ECHEVARRÍA, Javier, Fundamentos de antropología, EUNSA, Pamplona, 1998, pp. 61-82. El rostro es «una singular abreviatura de la realidad personal en su integridad». J. MARÍAS, Antropología metafísica, Revista de Occidente, Madrid, 1973, citado en ibidem, p. 66. Al respecto dice Yepes Stork: el rostro representa externamente a la persona. Se suele decir que «la cara es el espejo del alma»: el hombre no se limita a tener cara, sino que tiene rostro. El rostro humano, especialmente la mirada, es tremendamente significativo
Individuo en filosofía equivale a entidad, es la parte de un todo, en este sentido una persona puede ser un individuo pero no todos los individuos son personas. El derecho privado se ocupa de individuos en contraposición con el público que se ocupa del Estado en su relación con los individuos. En lenguaje jurídico se suele utilizar el término individuo porque es indeterminado, el individuo persona se hace 'sujeto de derecho' justamente cuando el derecho lo 'individualiza' en un hipotético normativo, es decir que lo dota de derechos y deberes. Entonces el individuo adquiere un status ${ }^{35} \mathrm{o}$ personalidad dependiendo el rol a desempeñar (el hipotético en el que se sitúe), padre, comprador, tutor, mandatario, cónyuge, etc. Este status se ejercita a través de una capacidad, es decir el individuo se 'sitúa' en determinada posición jurídica dependiendo si es 'capaz' o no y en ciertos casos si está 'legitimado' (autorizado por la ley) o no.

En psicología y sociología se habla de identidad, el conjunto de los roles o el mismo status pueden determinar la identidad del individuo, en el caso jurídico los dos roles más importantes que se desempeñan en el

e interpelante: cruzar la mirada con alguien es entrar en comunicación con él. (...) En muchas ocasiones ese mismo rostro es la comunicación pura de la intimidad. La expresión de la intimidad se realiza también mediante un conjunto de acciones expresivas. A través de ellas el hombre habla el lenguaje de los gestos: expresiones del rostro (desprecio, alegría), de las manos (saludo, amenaza, ternura), etc. A través de los gestos el hombre expresa su interior. Ibid.

35 Hemos querido dejar la escritura original del latín status porque es un término técnicamente más homogéneo en diferentes idiomas, utilizado también así en español pero le son equivalentes estado y estatus, y en algunos textos estatuto aunque ésta sea más bien una derivación de las primeras formas (este término está ligado al derecho de una comunidad-el estatuto de un municipio por ejemplo. Consignamos por ahora la definición de las Concordancias y motivos del Código Civil mexicano con el proyecto español de García Goyena, Biblioteca de Jurisprudencia, México, D.F. "Estado: es una calidad personal a la que la ley reconoce ciertos derechos, e impone deberes y restricciones" (p. 14). 
derecho público son el de ciudadano y el de nacional, que en el caso de algunos sistemas de derechos son equivalentes y en otros excluyentes, así es como se habla de derechos civiles como aquellos derechos que competen a los ciudadanos de una nación. ${ }^{36}$

Se advierte que la noción de persona está directamente relacionada con la libertad desde su origen. En eso radica la diferencia entre hombre y persona en la antigüedad. Tal es la causa de que los hombres no libres eran considerados los esclavos ${ }^{37}$, es decir, no considerados personas, lo mismo ocurre con las mujeres, porque en definitiva el reconocimiento de los derechos y las obligaciones, que necesariamente descansan en personas, supone reconocimiento de la libertad, cuya condición está unida al Estado.

Desde el periodo justinianeo y hasta la jurisprudencia medieval y renacentista continuó siendo válido el principio de que persona est homo in status quodam consideratus (el hombre considerado vinculado a un estado es persona). ${ }^{38}$

Como sabemos, la gran aportación de Roma a la cultura jurídica, no fue teórica sino práctica, conocemos los estudios de eclécticos como Cicerón, Séneca y Quintiliano ${ }^{39}$, que

${ }^{36}$ NARVÁEZ HERNÁNDEZ, José Ramón..., op. cit., p. 19

37 GAYOSSO Y NAVARRETE, Mercedes, Persona: naturaleza original del concepto en los derechos romano y náhuatl, Universidad Veracruzana, Veracruz, 1992, pp. 49-51.

${ }^{38}$ Ibidem, p. 51.

39 Cfr. CICERÓN, Las leyes, Instituto de Estudios Políticos, Madrid, 1970, 245 pp. SÉNECA, Lucio Anneo, Tratado de estudios morales, UNAM, México, 1991, 2 V. QUINTILIANO, Marco Fabio, Institución oratoria, CONACULTA, México, 1999, 360 p. retoman las enseñanzas griegas, son ellos los pilares del pensamiento romano. Así las cosas, la definición de persona en el derecho romano deriva de la noción de humanitas ${ }^{40}$.

En consecuencia, según el derecho civil, no todos eran personas, sino sólo aquellos que pertenecen al conjunto de hombres cuya participación era legítima dentro de la sociedad, porque eran libres y habían recibido la educación que les concede la humanitas. ${ }^{41}$ En Roma sucedía, por lo tanto, algo muy similar a lo que en Grecia. La noción de persona va ligada indisociablemente al nombre que se adquiere o se recibe después del nacimiento de parte de una estirpe que junto con otras constituye una sociedad y en virtud del cual el hombre queda reconocido y facultado con unas capacidades (papeles o «roles») que puede desempeñar, es decir, queda constituido como «actor» en un «escenario»-la sociedad-de forma que puede representar o ejercer las funciones $y$ capacidades que le son propias en el ámbito de la sociedad. ${ }^{42}$

Javier Hervada describe la influencia que ejerció el cristianismo en la configuración del concepto de persona a partir de la compilación justineana:

Así, por ejemplo, en el Digesto hay, entre otros, dos textos interpolados que muestran la idea cristiana de que la esclavitud no es natural y que por naturaleza todos los

${ }^{40}$ Cfr. Diccionario ilustrado Latino-..., op. cit., voz: humanitas, -atis, pp. 225-226. Los sentidos de humanitas son: humanidad, naturaleza humana, cualidad del ser humano, cultura espiritual, etc.

${ }^{41}$ Humanitas es el equivalente a la paideia griega. Cfr. Ibidem, p. 431.

${ }^{42}$ ARREGUI, Jorge Vicente, CHOZA, Jacinto..., op. cit., pp. 429-430. 
hombres son iguales, a la vez que la clara distinción entre ius naturale $y$ ius gentium (...). D. 12, 6, 64: «Si un dueño pagó su deuda a su esclavo después de manumitido, aunque lo hiciera creyendo [erróneamente] que se le podía reclamar aquella deuda por alguna acción, sin embargo, no podrá repetir, pues cumplió una obligación natural. Como la libertad es de derecho natural y la esclavitud ha sido introducida por el derecho de gentes, en la condición de razón de lo debido o indebido debe entenderse por naturaleza». D. 50, 17, 32: «Por derecho civil, los esclavos no son personas, pero no por derecho natural, pues por lo que respecta al derecho natural, todos los hombres son iguales». Son estos textos, además, una muestra de lo que fue común en el derecho romano y lo siguió siendo hasta fines de la Edad Moderna. El binomio derecho natural-derecho positivo no se entendía como un dualismo, esto es, como dos sistemas jurídicos coexistentes y a veces opuestos, sino en forma monista: lo positivo y lo natural aparecen como dos factores complementarios del orden jurídico, conjugándose con uno y otro armónicamente en la interpretación del derecho. El derecho natural aparece como un factor vivo y operante, como un elemento para encontrar, en armónica conjunción con el derecho positivo, la solución justa para el caso concreto. ${ }^{43}$

Con el advenimiento del cristianismo se promovió el reconocimiento de la persona en un sentido que supera el del derecho civil. Este momento coincide con la caída del Imperio Romano de Occidente y, por consiguiente, con el nacimiento de la Edad Media.

El concepto cristiano del mundo, al principio, fue (sic.) una tentativa para elevar la dignidad del ser humano, reconociendo en el mismo, sólo por su cualidad de tal, un principio divino y eterno, y conjuntando, por consiguiente, a todos los hombres en un orden de igualdad sobre la contingencia de su diversa suerte terrenal. ${ }^{44}$

${ }^{43}$ HERVADA, Javier, Historia de la ciencia del derecho natural, EUNSA, Pamplona, 1991, pp. 111-112.

${ }^{44}$ DEL VECCHIO, Jorge..., op. cit., p. 8.
El cristianismo como sustento filosófico influyó en la gestación de las ciencias humanas. La noción de persona experimentó un giro radical por las pretensiones filosóficas a las que se le sometió, de manera que su estudio comprendió no sólo el ámbito filosófico o teológico, sino que se remontó a una búsqueda de su más pura naturaleza a través de la metafísica. Desde luego con Aristóteles advertimos un intento de estudio metafísico - a partir de su aspecto gnoseológico y psicológico - sobre el hombre ${ }^{45}$, sus logros se ven reducidos, sin embargo, por el contexto de su época, el estagirita sostiene un tipo de esclavitud como parte de la polis ${ }^{46}$, desde la perspectiva de su época se puede entender como una condición a la que quedan reducidos aquellos que por la guerra o por condiciones personales no pueden ser considerados libres, es decir personas.

En contraste, para el cristianismo ninguna clase de esclavitud es justificante. La persona no tendría únicamente ese estatuto frente al derecho civil. El punto de partida en esta nueva concepción es la individualidad de la persona, por la cual, debido a esta característica, la persona es un absoluto. En otras palabras, se evidencia lo injustificado de considerar a la persona como tal frente al derecho, dejándola desprovista de un fundamento ontológico.

${ }^{45}$ Cfr. ARISTÓTELES, Sobre el alma 412 a - 424 b, Introd., trad., y notas de Tomás Calvo Martínez, Gredos, Madrid, 1999.

${ }^{46}$ Una explicación minuciosa acerca del sentido de la esclavitud en Aristóteles, se encuentra en ASPE ARMELLA, Virginia, Las aporías fundamentales del periodo novohispano, Sello Bermejo, CONACULTA, México, 20002, pp. 123-130. 
Mas allá de la difundida idea de que la Edad Media fue oscurantista, subyace un concepto teológico casi predeterminante de las ciencias y del mundo en general. Sin embargo, pese al teocentrismo característico de la época - cuyo análisis rebasa los objetivos de este trabajo -, importantes aportaciones son rescatables, como ya hemos mencionado. ${ }^{47}$

En este orden de ideas Boecio (480-526 d.C.) en su obra, De Duabus Naturis, se adentra en el estudio de la esencia de la persona, adelantándose a Kant (1724-1804), quien concibe a la persona como fin en sí misma. El pensador romano, por su parte, la define como sustancia individual de naturaleza racional ${ }^{48}$, siglos de historia y de reflexión median entre ambos autores, lo cierto es que para entender el concepto de persona en su tránsito por los autores es necesario hacerse cargo de las influencias que están presentes contribuyendo a la configuración actual de dicho competo.

A la Edad Media sucedió la Moderna, y tras el pensamiento de Descartes nada fue lo mismo. Posteriormente, la recuperación de los clásicos se ha planteado a pesar de ello, pero desde la perspectiva racionalista. El parteaguas fue la duda metódica del francés. ${ }^{49}$

${ }^{47}$ Cfr. DEL VECCHIO, Jorge..., op. cit., pp. 12-13.

48 BOECIO, Severino, De Duabus Naturis, PL 64, 1343-1344. Con esta definición sintetiza las nociones del pensamiento clásico acerca del hombre, principalmente las de Sócrates y Platón; le llama sustancia individual porque cada ser humano, antes que ser parte de una especie, es en sí mismo un individuo. Un segundo aspecto de la esencia de la persona es "ser racional" pues la trascendencia de su individualidad radica en su intelectualidad, su capacidad de conocimiento, que se coimplica con la voluntad.

${ }^{49}$ Cfr. DEL VECCHIO, Jorge..., op. cit., pp. 16-22.
El derecho a la duda - cuyo supuesto consistía en una sola certeza, la del sujeto que duda-se había entonces afirmado en las ciencias naturales, con la exigencia de la observación experimental, y en la religión, con la exigencia del libre examen y de la interpretación individual de las Escrituras; y, por lo tanto, sólo de la Filosofía podía obtener una explicación sistemática suficiente. En esto radica la inmensa importancia de la obra cartesiana, la cual, aunque en sus conclusiones haya sido dogmática, en su primitivo origen fue gloriosa e insuperablemente crítica. ${ }^{50}$

Ahora bien, es de destacar que el paralelismo que más arriba se estableció entre Boecio y Kant no persigue la intención de cometer una arbitrariedad con la historia, simplemente, sino llamar la atención sobre la permanencia de la misma inquietud tras el reconocimiento de la dignidad de la persona a pesar de tan drástico giro en la visión del mundo y del hombre.

Con la doctrina de la sustancialidad del alma de Boecio, se reconoce el valor absoluto de la persona humana en el aspecto teórico, de manera que este principio debe reflejarse en las doctrinas de la Ética y la Política. Lo que por un lado era un principio ontológico y cognoscitivo, por otro lado tenía que ser un principio moral y jurídico. La certeza de que el hombre, por su propia esencia, es algo absolutamente prius, es decir, una sustancia autónoma, es útil tanto para la Gnoseología como para el Derecho y es por igual aplicable a éste y aquélla. ${ }^{51}$

Cuando la definición boeciana de persona se funde con la noción romano-estoica de humanitas, a la que se aludió anteriormente, da lugar a la noción de "persona humana»,

\footnotetext{
${ }^{50}$ Ibidem, p. 20.

${ }^{51}$ Ibidem, pp. 22-23.
} 
que se predica absolutamente de todos los hombres y designa la singularidad de cada ser humano y la igualdad de todos ellos. Ahora la persona se concibe como un absoluto, en sí, más allá de toda relación jurídica y de cualquier condición social. La persona, y su característica la dignidad, aparecen como un cierto absoluto. Como es obvio, esta configuración de la noción metafísica de persona es correlativa con la crisis del derecho a finales de la edad media. Cuando la noción metafísica de persona como absoluto más allá de cualquier reconocimiento jurídico se proyecta de nuevo sobre el ámbito del derecho, surge un derecho, llamado habitualmente derecho natural, allende todo derecho positivo, que es el reconocimiento del valor ontológico de la persona humana y de unos derechos que le competen intrínsecamente. Ahora, desde esos derechos de la persona se puede juzgar la legitimidad de cualquier sistema jurídico-positivo, lo cual supone, como es obvio, una relativización del derecho. ${ }^{52}$

La época en que Kant vive y expone su pensamiento, coincide con el Renacimiento y la Ilustración, entonces coexisten la concepción teocéntrica y el racionalismo, en este momento histórico el pensamiento jurídico descansaba en la afirmación de la existencia de sólo fines humanos para el Estado y que su validez se funda, no ya en una voluntad superior y en una finalidad ultraterrenal, sino en las exigencias de los individuos que lo componen, en consecuencia, que su actividad debe quedar limitada a lo que reclame la conveniencia de los mismos. ${ }^{53}$

Lo anterior no significa que Kant se identificara con el realismo, pese a que se proponía desentrañar la finalidad de las cosas, para este autor, la realidad es lo que para la

52 ARREGUI, Jorge Vicente, CHOZA, Jacinto..., op. cit..., p. 431.

${ }^{53}$ DEL VECCHIO, Jorge..., op. cit., p 26. persona representa. Su doctrina se integra en un idealismo gnoseológico, apoyado en el racionalismo ${ }^{54}$, en consecuencia la obra de Kant no tiene mayor reparo en este estudio porque la parte que nos ocupa es la entidad de la persona, a la que Kant define como un fin en sí mismo, por lo que formuló el siguiente imperativo: Obra de tal modo que uses la humanidad, tanto en tu persona como en la persona de cualquier otro, siempre como un fin al mismo tiempo y nunca solamente como un medio. ${ }^{55}$ Esta tesis aparentemente ofrece una solución al dilema del binomio "persona frente al derecho", hemos de advertir, sin embargo, que tanto en el plano ontológico como - por consecuencia - en el plano jurídico, la persona es un fin en sí mismo frente a los demás. El racionalismo que caracteriza al Renacimiento y las doctrinas que le sucedieron desvinculan los elementos teológicos de los éticos, Kant, sin embargo, tiene el mérito de plantear, como ya hemos mencionado, que la persona es un fin en sí misma apoyándose únicamente en la razón. Es persona siempre; incluso frente al derecho civil, cualquier hombre es persona, independientemente de las particularidades raciales, religiosas, políticas o de estado de salud.

Consecuentemente, la Filosofía de Kant representa la unión y síntesis de los (sic) diversos motivos, teóricos y prácticos, del subjetivismo racionalista. Por un lado, dicha doctrina señala la más completa elevación sistemática del principio crítico cartesiano,

54 ABBAGNANO, Nicola, Diccionario de filosofía, FCE, México, 1998, voz: kantismo, p. 718.

55 KANT, Emmanuel, Fundamentación de la metafísica de las costumbres, Espasa Calpe, México, 1967, p. 84. 
por el cual la mente humana busca introspectivamente sus propias leyes y encuentra en sí misma el fundamento a priori de toda experiencia. Por otro lado, reconoce en la conciencia positiva una absoluta dignidad ética, y declara al hombre fin en sí mismo. De este modo, en la doctrina política de Kant, los derechos esenciales de la persona corresponden a las prerrogativas esenciales de la razón, descubiertas por su crítica gnoseológica. ${ }^{56}$

Como era de esperarse, la consecuencia inmediata, únicamente del razonamiento ético kantiano y no de sus reflexiones gnoseológicas, supondría el reconocimiento del derecho natural como anterior y completamente independiente del positivo. Sin embargo, sucedió lo contrario porque tiempo atrás, el filósofo francés Descartes había sembrado en el ámbito de la reflexión jurídica la semilla del relativismo en la metodología moderna, o lo que Del Vecchio y Orestano han llamado subjetivismo:

$\mathrm{Al}$ respecto es elocuente la siguiente cita de Mercedes Gayosso y Navarrete: ya que considero a R. Orestano como uno de los más profundos críticos del desarrollo del fenómeno, me permito transcribir su opinión. Él afirma que "las cosas comenzaron a cambiar en el curso del siglo XVIII, cuando bajo el impulso ideológico del individualismo iusnaturalista se pretendieron hacer coincidir el status hominis naturalis y el status hominis civiles, esto es, la noción de un hombre como referencia natural y la noción de persona como referencia jurídica, sosteniéndose que todo hombre sería de por sí portador de 'derechos subjetivos', todos recayendo en su 'potestad de querer', elevada a identificación natural de su personalidad y a elemento motor de las relaciones jurídicas de las que él era la cabeza". Continúa su reflexión, haciendo alusión a que esta fusión y confusión de conceptos dio lugar a la hipótesis de que el hombre, en cuanto ser jurídico, depende de la preexistencia de normas sociales y no de su condición natural de hombre. Y agrega "este paso de una concepción esencialmente objetivista del derecho a una concepción eminentemente subjetivista, se realizó sobretodo en la construcción de la pandectística alemana desde fines del Siglo XVIII y el XIX, en el marco de una elaboración sistemática de la doctrina general del derecho privado". ${ }^{57}$

Pese a que la subjetividad de la persona es innegable, pues como el mismo término lo indica: ser sujeto implica subjetividad. La individualidad da la pauta para la subjetividad. Sin embargo, el hombre no es un ser solo, ajeno o ausente a cualquier influencia, es decir, un en sí en su relación con los demás.

La dicotomía fundamental en la cual se articula la civilización contemporánea, toma un rostro siempre más definido con el pasar del arreglo económico capitalístico, es la distinción entre quién tiene y quién no tiene; a la civilización del tener esto basta y sobra, ya que tanto más se es cuanto más se tiene, con una conmixtión y casi fusión entre dos dimensiones de por sí distantes. La propiedad no es solamente fuente de riqueza, de bienestar y también de poder; sufre una elevación jamás conocida antes de ahora, entra con prepotencia en el terreno celoso de la moral. Los individuos, en cuanto homines oeconomici, serán separados uno del otro precisamente por fuerza del fin esencial de la propia acción, la ganancia, ya que mi ganancia no prevé la consideración del otro, ni mucho menos bajo el grosero perfil de la ganancia del otro. Las libertades, de las cuales se cubre el individuo, resienten esta insularidad, se miden sobre su subyacente hipertrofia y la reflejan [...] La reducción de la complejidad sociopolítica al binomio Estado/individuo pareció satisfactorio, definitivamente satisfactorio, pero sacrificó

${ }^{57}$ GAYOSSO Y NAVARRETE, Mercedes..., op. cit., p. 53.

${ }^{56}$ DEL VECCHIO, Jorge..., op. cit., p. 34. 
de hecho la riqueza plural de la sociedad, la hizo de algún modo manca, incompleta, inexpresiva. Hoy, existe la exigencia indilatable de pensar (y acoger) el sujeto al interno de un tejido social restituido en toda su complejidad y también en su entera capacidad de manifestar y realizar sus múltiples potencialidades obstaculizadas por el reduccionismo estatalista e individualista moderno". ${ }^{58}$

Consistente con el subjetivismo moderno, y ante la negación de la naturaleza ontológica de la persona y sus derechos, surgió el Código Napoleónico (1804), el cual no concedía el estatuto de persona a todo hombre concebido, sino que se adquirían los derechos a partir del nacimiento. Esta tesis fue apoyada por Savigni. No obstante, como ya lo hemos explicado, la personalidad jurídica es natural, y no creada por un orden jurídico que puede cambiar de parecer en el paso del tiempo. ${ }^{59}$

Debemos estar atentos porque en el derecho moderno el 'individuo' se convierte en pretexto, la etimología preferida de esta época es la de indiviso, no divisible, átomo, y hemos visto ya el peligro que conlleva aislar a la persona. En este sentido individuo puede llegar a contraponerse a persona, el primero es autónomo y por tanto estéril, la segunda es fruto de las relaciones, son las diversas representaciones de un ser humano frente a otros. ${ }^{60}$ Dos ideas, si se quiere, pero del

58 GROSSI, Paolo. "Le molte vite del giacobinismo giuridico (ovvero: la 'carta di Nizza' il progetto di 'Costituzione europea', e le insodisfazioni di uno storico del diritto)" en: Rivista di scienze giuridiche Jus, no. 3 , 2003, pp. 405-422, ahora en castellano en: Derecho, sociedad, Estado. Paolo GROSSI en México, ELD, México, 2004.

59 Cfr. GAYOSSO Y NAVARRETE, Mercedes..., op. cit., pp. 54-57.

60 Contraria es la postura de Cattaneo que en el ámbito penal opina que "individuo y persona pueden ser considerados como sinónimos. No sólo: si para Boecio la persona es 'individua substantia', Kant - un colocarse en una o en otra dependerán muchas cosas. ${ }^{61}$

En el desarrollo de las páginas de este trabajo, hemos sostenido, en plena identificación con la tradición realista clásica, que la persona es sujeto de derechos y obligaciones, sin embargo esta realidad universal debe adecuarse a las circunstancias concretas de cada persona, en consecuencia, los derechos y las obligaciones son los mismos en tanto la persona se coloque en el supuesto jurídico, esta sutil diferencia roza los límites del contenido moral de los actos, lo que nos permite advertir un aspecto muy diferente y más profundo en la valoración ética en relación con la jurídica. Por ejemplo, la mayoría de edad trae consigo para el sujeto mayor libertad de acción, de ejercicio y por lo tanto mayor responsabilidad.

Comúnmente se entiende por capacidad jurídica la aptitud para ser titular de derechos $y$ obligaciones $y$, en general, de relaciones jurídicas. La capacidad jurídica, así entendida, es una cualidad esencial de la persona y

filósofo que ha sido considerado muchas veces como un teórico del individualismo en sentido negativo - usa constantemente justo el término 'persona' para indicar la personalidad del ser humano, dotada de dignidad y de libertad interior" CATANEO, Mario A., Pena, diritto e dignità umana, Gappichelli, Torino, 1990, p. 287. Así el término individuo no solamente sería equiparado al de persona sino que designará su esencia y una salvaguarda frente a las "prevaricaciones tiránicas de las sociedades intermedias" (p. 286) el que sea una persona individuo lo hace según Cattaneo más humano y menos parte de un grupo que lo ata a sus reglas y lo condena a ellas. Si se continúa la lectura del libro se entiende el por qué de esta elección: El modo de humanizar las penas es el de individualizarlas (pp. 288 y ss). Nos parece que existe una ligera confusión entre individualización y equidad, entre individuo e individualidad o elemento individual.

${ }^{61}$ NARVÁEZ HERNÁNDEZ, José Ramón..., op. cit., p. 21 
corresponde siempre a la misma, cualesquiera que sean sus circunstancias -infante, mayor de edad, loco, extranjero, etc.-. Otra cosa es la titularidad efectiva de derechos que, en el ámbito patrimonial y como es obvio, no viene asegurada por la condición de persona, si bien cabe que ello sea así, hasta el punto de que un recién nacido, con capacidad jurídica innegable, puede muy bien ser titular de una inmensa fortuna. Otra cosa es, en fin, la posibilidad de ejercitar los derechos que a uno puedan corresponder, posibilidad que, como veremos, está en función -aquí sí-de determinadas circunstancias, cual la menor edad, valga por caso. ${ }^{62}$

En consecuencia, al predicarse de todos los hombres el ser persona, los derechos y las obligaciones son universales. La lucha por la objetiva formulación de los presupuestos jurídicos en que éstos se contienen y su correspondiente respeto por parte del Estado supone la previa consideración del sustrato moral que en definitiva inspira los enunciados normativos y su aplicación.

El hombre aislado no puede cumplir su destino; la sociedad es su complemento y ofrece al hombre las posibilidades de su perfeccionamiento. Esta correlación que existe entre el hombre y la sociedad, determina el principio que existe entre hombre $y$ sociedad, determina el principio de igualdad, que significa, no la existencia de ser igual a los demás, sino "el reconocimiento de una identidad esencial entre los hombres y la oferta de las mismas oportunidades para el desenvolvimiento de las personalidades". ${ }^{63}$

${ }^{62}$ ROGEL VIDE, Carlos, Derecho a la persona, Manuales jurídicos de bolsillo, Bosch Editor, Barcelona, 1998, p. 12.

${ }^{63}$ DELACUEVA, Mario, "Prólogo" en CAMPILLO SÁINZ, JOSÉ, Derechos fundamentales de la persona humana, Comisión Nacional de Derechos Humanos, México, 1995, pp. 16-17.
La persona es la causa eficiente de la sociedad, es ella quien protagoniza las relaciones y las mediaciones, este fluir interminable ocurre en el contexto de unas exigencias implícitas en su naturaleza racional y social a un tiempo, y es precisamente el espacio de estas reflexiones, de donde deviene la exigencia ética de su consideración, es decir, el derecho no se reduce a la formulación de unos enunciados que conducen la actividad societaria, esto ocurre en la superficie del orden social, lo que se encuentra en el fondo, animando e inspirando los razonamientos jurídicos, es una concepción ética que soporta y fundamenta las exigencias de los razonamientos jurídicos concretos.

\section{REFERÊNCIAS}

ABBAGNANO, Nicola, Diccionario de filosofía, FCE, México, 1998, voz: kantismo, p. 718.

Adelantamos una definición de Legalismo de Silvia Gasparini: "Instrumento de disimulación de desigualdades sustanciales" Appunti minimi di storia del diritto, 2. Età moderna e contemporanea, Imprimitur, Padova, 2002, p. 214.

ARISTÓTELES, Sobre el alma $412 a-424 b$, Introd., trad., y notas de Tomás Calvo Martínez, Gredos, Madrid, 1999.

ARREGUI, Jorge Vicente, y CHOZA, Jacinto, Filosofía del hombre, una antropología de la intimidad, Universidad de Navarra, RIALP, Madrid, 1993.

ASPE ARMELLA, Virginia, Las aporías fundamentales del periodo novohispano, Sello Bermejo, CONACULTA, México, 20002, pp. 123-130.

BERDIAEFF, Nicolás, Una nueva edad media. Reflexiones acerca de los destinos de Rusia y Europa, Apolo, Barcelona, 1933, pp. 11-24.

BERLÍN, Isaiah, El fuste torcido de la humanidad. Capítulos de historia de las ideas, Península, Barcelona, 1992, pp. 85- 101. 


\section{BIBLIOTECA DE JURISPRUDENCIA,}

México, D.F. "Estado: es una calidad personal a la que la ley reconoce ciertos derechos, e impone deberes y restricciones" (p. 14).

BOECIO, Severino, De Duabus Naturis, PL 64, 1343-1344.

CATANEO, Mario A., Pena, diritto e dignità umana, Gappichelli, Torino, 1990, p. 287.

CICERÓN, Las leyes, Instituto de Estudios Políticos, Madrid, 1970, 245 pp. SÉNECA, Lucio Anneo, Tratado de estudios morales, UNAM, México, 1991, 2 V. QUINTILIANO, Marco Fabio, Institución oratoria, CONACULTA, México, 1999, 360 p.

DE LA CUEVA, Mario, "Prólogo" en CAMPILLO SÁINZ, JOSÉ, Derechos fundamentales de la persona humana, Comisión Nacional de Derechos Humanos, México, 1995, pp. 16-17.

DEL VECCHIO, Jorge, Persona, Estado y Derecho, Instituto de Estudios Políticos, Madrid, 1957.

Diccionario de ética y filosofía moral, Fondo de Cultura Económica, México, 1997, V. I, voz: Identidad moral, p. 767.

Diccionario Griego-Español, Editorial Sopena, Barcelona, 1999, voz: u4pokiemai, (hipokeímenon, es el participio pasivo), p. 1441.

Diccionario ilustrado Latino-Español, EspañolLatino, VOX, Barcelona, 1999, voz: persona, -ae.

Diccionario Manual Vox, Griego-Español, Barcelona, 1995, voz: u9to/stasij ewj.

FORMENT, Eudaldo, Personalismo medieval, Edicep, Valencia, 2002, p. 275.

GAYOSSO Y NAVARRETE, Mercedes, Persona: naturaleza original del concepto en los derechos romano y náhuatl, Universidad Veracruzana, Veracruz, 1992.

GROSSI, Paolo, Dalla società di società alla insularità dello Stato fra medioevo el età moderna, Instituto Universitario Suor Orsola Benincasa, Napoli, 2003, p.33 y ss.

GROSSI, Paolo, L'ordine giuridico medievale, Laterza, Roma-Bari, 2001, p. 85.
GROSSI, Paolo. "Le molte vite del giacobinismo giuridico (ovvero: la 'carta di Nizza' il progetto di 'Costituzione europea', e le insodisfazioni di uno storico del diritto)" en: Rivista di scienze giuridiche Jus, no. 3, 2003, pp. 405-422, ahora en castellano en: Derecho, sociedad, Estado. Paolo GROSSI en México, ELD, México, 2004.

HERVADA, Javier, Historia de la ciencia del derecho natural, EUNSA, Pamplona, 1991, pp. 111-112.

HOYOS CASTAÑEDA, Ilva Myriam, $L a$ dimensión jurídica de la persona humana, Universidad de la Sabana, Colección Ensayos no. 3, Bogotá, 1990.

KANT, Emmanuel, Fundamentación de la metafísica de las costumbres, Espasa Calpe, México, 1967, p. 84.

NARVÁEZ HERNÁNDEZ, José Ramón, La persona en el derecho civil (historia de un concepto jurídico), Porrúa, México, 2005.

Nuevo Diccionario Jurídico Mexicano, UNAM, Porrúa, México, 2001, t. IV, voz: persona.

PÉREZ VARELA, Víctor Manuel, Ser más humano, reflexiones sobre ética y derecho, Universidad Panamericana, Porrúa, México, 2005.

PLATAS PACHECO, María del Carmen, Filosofía del Derecho, Analogía de proporcionalidad, Porrúa, 2003, pp. 1-53.

REALE, Giovanni y ANTISERI, Darío, Historia del pensamiento filosófico y científico, T. III, Barcelona, Herder, 1995, pp. 795-797,

ROGEL VIDE, Carlos, Derecho a la persona, Manuales jurídicos de bolsillo, Bosch Editor, Barcelona, 1998, p. 12.

YEPES STORK, Ricardo, ARANGUREN ECHEVARRÍA, Javier, Fundamentos de antropología, EUNSA, Pamplona, 1998, pp. 61-82. El rostro es «una singular abreviatura de la realidad personal en su integridad». J. MARÍAS, Antropología metafísica, Revista de Occidente, Madrid, 1973, citado en ibidem, p. 66. 